\title{
Sobre el valor de la amistad y su conflicto potencial con la moral. Una revisión del debate contemporáneo
}

\author{
MARTÍN DAGUERRE \\ Facultad de Humanidades y Ciencias de la Educación \\ Universidad Nacional de La Plata \\ daguerre12345@yahoo.com.ar
}

\begin{abstract}
Resumen: En el debate contemporáneo en torno a la amistad se distinguen dos posiciones: una centrada en el tipo de persona que el amigo debe ser y otra que se centra en la historia de la relación entre dos personas que se consideran amigas. En el presente trabajo se defiende, en cambio, una concepción de la amistad centrada en el tipo de relación que la amistad es. Desde esta última concepción es posible sostener el valor intrínseco de la relación sin necesidad de admitir que las obligaciones especiales propias de la amistad pueden entrar en conflicto con las obligaciones morales.

Palabras clave: amistad impersonal, relación, disposición, virtud, conflicto de obligaciones
\end{abstract}

\begin{abstract}
Two accounts of friendship can be found in the contemporary debate: one of them is centered on the type of person the friend must be, the other is centered on the history of the relationship between two people that consider themselves friends. In this paper I defend a different account, centered on the type of relationship a friendship is. This account allows us to affirm the intrinsic value of the relationship, without having to admit that the special obligations arising from friendship can conflict with moral obligations.
\end{abstract}

Key words: impersonal friendship, relationship, disposition, virtue, conflicting obligations

No resulta difícil aceptar que la amistad implica una relación de afecto y cuidado mutuo, una relación en la cual la preocupación por el otro no deriva de consideraciones instrumentales en torno a beneficios estrictamente personales. Pero cuando se trata de definir más concretamente la relación, surgen varios puntos de discrepancia: ¿exige la relación que los implicados sean virtuosos?, ¿qué lugar ocupan factores psicológicos o históricos contingentes, como una historia compartida que haya dado lugar a sentimientos especiales entre los amigos?, ¿pueden las exigencias de la amistad entrar en conflicto con nuestras obligaciones morales? y, más fundamentalmente, ¿por qué es valiosa la relación de amistad? 
En el debate contemporáneo pueden distinguirse claramente dos posiciones, cada una de las cuales ofrece respuestas distintas a las preguntas anteriores. La primera pone el acento en ciertos rasgos del amigo que justifican que uno se preocupe por él más que por los demás. Más específicamente, según esta posición, es el hecho de que la otra persona sea virtuosa lo que justifica que uno fomente la amistad con ella y se preocupe más por ella que por las personas no virtuosas. Este planteamiento supone una concepción de la virtud y de lo valioso independiente de la relación misma, a partir de la cual se justifica la amistad. La segunda posición entiende que en la generación de relaciones de amistad intervienen factores arbitrarios; a partir de la coincidencia en la concepción de vida buena, o en el sentido del humor o en el gusto por ciertas prácticas, se generan relaciones de afecto mutuo, las cuales, una vez establecidas, generan obligaciones en los amigos. No es el hecho de que el otro sea virtuoso, sino el que sea mi amigo, lo que justifica mi mayor consideración por su vida. Por otra parte, ambas posiciones coinciden en que en la amistad se desea el bien del amigo por el amigo mismo; pero discrepan, como veremos, en la interpretación de tal exigencia.

En lo que sigue presentaré ambas posiciones y argumentaré que ambas son insatisfactorias. La primera, porque le asigna a la relación de amistad un valor instrumental y no intrínseco; la segunda, porque le otorga a factores contingentes un peso normativo injustificado. Ofreceré, entonces, una tercera concepción, ya no centrada en el tipo de persona, ni en aspectos contingentes de la relación, sino en el tipo de relación. Sostendré que valoramos la relación de amistad en cuanto que implica un afecto mutuo y una disposición recíproca a realizar un conjunto de acciones. Otorgamos a estas relaciones un valor intrínseco y no como medio para la persecución de fines independientemente valiosos. Y si bien tal afecto y tal disposición pueden haber tenido su origen en acontecimientos contingentes, no son éstos los que otorgan valor a la relación, sino que ésta tiene valor en sí misma, más allá de cuál haya sido su origen.

\section{Concepción centrada en el tipo de persona}

Diane Jeske, si bien es crítica de la primera concepción, ofrece una buena síntesis de ella:

Consideremos la afirmación de Aristóteles en el sentido de que "sólo lo que es bueno es digno de amor [lovable]. Lo que es malo no es digno de 
amor, y no debe ser amado" (1165b15). Ciertas personas, las virtuosas, tienen caracteres valiosos. Lo que es valioso o bueno es digno o merecedor de consideración [concern]. Por lo tanto, los virtuosos son dignos o merecedores de consideración. Estamos justificados en hacernos amigos de los virtuosos porque ellos son objetos apropiados de las actitudes que en parte constituyen la amistad [...]. De modo que la naturaleza de los caracteres de las personas virtuosas justifica que tengamos mayor consideración por dichas personas que la que tenemos por los no-virtuosos.

Ser amigo de una persona implica ayudarla a promover sus fines. Sólo si mi amigo es virtuoso tendré la garantía de que sus fines son valiosos y dignos de ser promovidos. ${ }^{1}$

Sólo los virtuosos son dignos de una consideración especial y, dado que la amistad implica una consideración especial por el amigo, sólo corresponderá ser amigo del virtuoso. A su vez, la consideración especial con el virtuoso viene justificada por el hecho de que los fines del virtuoso son dignos de ser promovidos, de modo que al ayudar al virtuoso estamos contribuyendo a conformar un estado de cosas valioso. Jennifer Whiting, en su trabajo "Impersonal Friends", ha sido quien con mayor determinación ha asumido la defensa de este enfoque. Desarrolla su postura en oposición a la que llama "posición egocéntrica", según la cual lo que justifica que yo me preocupe por mi amigo es la relación que él tiene conmigo. Para la posición egocéntrica, el mero hecho de que alguien sea mi amigo justifica que me preocupe por él, más allá de sus características personales. El problema de la posición egocéntrica, según Whiting, es que si lo que justifica mi mayor preocupación por mi amigo es el hecho de que se encuentra en cierta relación conmigo, ¿en qué medida podría decirse que me preocupo por mi amigo por él mismo? Si nos preocupamos por un amigo por sí mismo, se supone que lo hacemos en virtud de que es una persona digna de una consideración especial, independientemente de la relación que tenga con nosotros. Para Whiting, "la sustancia o contenido del carácter del otro (como algo distinto de su relación con el nuestro) es lo que fundamenta nuestra consideración". ${ }^{2}$

El hecho de que la amistad se entable con una persona virtuosa vuelve valiosa la relación en la medida en que a través de ésta uno aumenta su dedicación a fines valiosos (que son los propios de una persona virtuosa). Tal concepción de la amistad justifica el tener amigos

${ }^{1}$ D. Jeske, "Friendship, Virtue, and Impartiality", p. 58; la traducción de las citas de esta obra es mía.

${ }^{2}$ J. Whiting, "Impersonal Friends", p. 11 (la traducción de las citas de esta obra es mía).

Diánoia, vol. LV, no. 64 (mayo 2010). 
si de ese modo se contribuye más acabadamente a la persecución de fines valiosos, pero también exige que seamos amigos únicamente de los virtuosos. Si la amistad exige que contribuya a la satisfacción de los fines de mi amigo, contraer esta relación con una persona viciosa me comprometería con fines indignos de ser perseguidos.

Ahora bien, muy probablemente nos resulte imposible ser amigos de todas las personas virtuosas en la medida en que toda relación de amistad implica, como mínimo, dedicar cierta cantidad de tiempo a actividades compartidas con el amigo, y nuestro tiempo es necesariamente finito. Surge, entonces, un lugar para la contingencia en la determinación de quiénes serán nuestros amigos. Para Whiting, aunque todas las personas virtuosas son dignas de nuestra amistad, "factores contingentes y que no constituyen una justificación pueden entrar en juego en la determinación (y, por lo tanto, en la explicación) de cuál de los muchos candidatos merecedores deviene de hecho mi amigo". ${ }^{3}$ Los factores arbitrarios desempeñan aquí un papel al explicar, aunque sin justificar, que entablemos una relación de amistad con una persona virtuosa antes que con otra también virtuosa. ${ }^{4}$

Si bien el surgimiento de una relación de amistad con una persona virtuosa en particular está determinado por hechos contingentes que lo explican sin justificarlo, lo cierto es que, una vez establecida la amistad, está justificado continuar con esa relación y no tratar al amigo como un bien fungible, esto es, como a un objeto que puede ser reemplazado por otro similar, sin pérdida de valor. Se generan obligaciones especiales con el amigo por la siguiente razón:

La persona virtuosa [...] tiene generalmente un conocimiento más íntimo de sí misma y de aquellos con quienes ha pasado más tiempo de manera íntima, y está generalmente en mejor posición para cultivar y promover los fines que valora genéricamente, en su propia persona y en la de sus íntimos, que en la persona de aquellos con los que tiene relaciones menos íntimas. ${ }^{5}$

${ }^{3}$ Ibid., p. 7.

${ }^{4}$ Obsérvese que, para esta posición, los factores arbitrarios tienen su lugar en la determinación de quién, entre todas las personas virtuosas, será nuestra amiga. En contraste, los defensores de la segunda posición, que no aceptan restringir las relaciones de amistad a las personas virtuosas, otorgan su lugar a los factores arbitrarios en la determinación de quién, entre todas las personas, será nuestra amiga. Véase D. Jeske, op. cit., y D.O. Brink, "Eudaimonism, Love and Friendship, and Political Community".

${ }^{5}$ J. Whiting, op. cit., pp. 21-22.

Diánoia, vol. LV, no. 64 (mayo 2010). 
No da lo mismo cambiar un amigo de años por otra persona igualmente virtuosa, ya que por razones epistemológicas (por nuestro mayor conocimiento del amigo, desarrollado a través de la interacción prolongada) estamos en mejores condiciones para ayudar y ser ayudados por él en nuestra búsqueda común de la virtud de lo que lo estaríamos para ayudar o ser ayudados por un virtuoso extraño.

Al analizar la posición de Whiting, Helm Bennett vuelve clara la virtud de enfoques como ése:

Si intentamos justificar la continuidad de la amistad apelando al hecho de que el amigo es esta persona en particular, con una relación histórica particular conmigo, entonces parece que estamos apelando a propiedades subjetivas y meramente idiosincrásicas, las cuales pueden explicar pero no pueden justificar esa amistad. Esto parece implicar que la justificación en general requiere una apelación al hecho de que el amigo sea un tipo de persona, poseedor de propiedades generales y objetivas que otros podrían tener también. ${ }^{6}$

El problema más señalado de posiciones como la de Whiting es que no le reconoce valor intrínseco a las relaciones de amistad, sino sólo un valor instrumental. Como señala Brink: "Estas concepciones de la consideración especial desde una perspectiva imparcial o impersonal [...] asignan sólo una importancia extrínseca a la consideración especial; la consideración especial es valiosa sólo en la medida en que tiende causalmente a promover la felicidad o la virtud". ${ }^{7}$ En el mismo sentido va la crítica de Jeske, para quien todos, incluso los no virtuosos, pueden tener amigos, y para quien los amigos no han de ser, en consecuencia, necesariamente virtuosos:

Nos encontramos, a veces por razones claramente enunciables, y a veces no, envueltos en relaciones de amistad, pero una vez que nos encontramos implicados en esas relaciones, tenemos razones para preocuparnos [care] por el otro que no teníamos antes, razones que no tienen nada que ver con nuestra capacidad para promover lo valioso, o con las formas en que podemos responder de manera apropiada a la virtud de otras personas. Nuestros deberes de consideración especial continuada supervienen a nuestras relaciones, y no se derivan de ningún deber más general. ${ }^{8}$

\footnotetext{
${ }^{6}$ H. Bennett, "Friendship"; la traducción de las citas de este artículo es mía.

${ }^{7}$ D.O. Brink, op. cit., p. 269; la traducción de las citas de este artículo es mía.

${ }^{8}$ D. Jeske, op. cit., p. 62.
} 
Ferdinand Schoeman considera que el planteamiento impersonal del tipo defendido por Whiting corresponde más a un análisis del respeto que a uno de la amistad:

Cuando amamos la bondad de alguien, lo más apropiado sería quizás caracterizar esa relación como una de respeto, no amor ni amistad. En ese caso, no nos importa la persona por sí misma, sino por su excelencia o virtud. Debemos diferenciar el respetar los valores de una persona del amar a la persona. ${ }^{9}$

\section{Concepción centrada en factores contingentes de la relación}

Para los defensores del segundo enfoque que mencioné al comienzo, uno puede querer al otro, ser su genuino amigo, aun cuando aquél no posea las excelencias de carácter consideradas fundamentales por la anterior posición. Querer a un amigo no implica querer sus fines; podemos muy bien sentir afecto por el otro, y por eso mismo intentar modificar sus actuales motivaciones en caso de que las consideremos perjudiciales para él. Precisamente, dado el afecto que tengo por mi amigo, encuentro razones para preocuparme por combatir sus vicios, su inmadurez. Es a partir de la existencia de la relación de amistad como se generan las obligaciones propias de la relación.

Los factores causales que pueden explicar la generación de una relación particular de amistad son innumerables, y la excelencia de carácter no es más que uno de ellos. Como señala Jeske:

A menudo comenzamos a interactuar con personas con las que creemos tener mucho en común, sólo para descubrir más tarde que difieren significativamente de nosotros. Pero a través de estas interacciones, desarrollamos un afecto y una preocupación por esa otra persona; descubrimos que somos amigos, antes de entender realmente el carácter del otro. ${ }^{10}$

La idea es que la amistad implica afecto y cuidado mutuos, y todas las personas son dignas, en principio, de tal afecto y cuidado. En principio, todos son dignos de entrar en una relación de amistad, no sólo los virtuosos; ${ }^{11}$ por lo tanto, no requiere justificación el que yo sea amigo de

${ }^{9}$ F. Schoeman, "Aristotle on the Good of Friendship", p. 278; la traducción de las citas de este artículo es mía.

${ }^{10}$ D. Jeske, op. cit., p. 71.

${ }^{11}$ Digo "en principio" porque suele hacerse la salvedad de que quien es irremediablemente vicioso difícilmente puede ser amigo de alguien. 
esta persona antes que de aquélla; no es necesario que intente demostrar que mi amigo posee ciertas cualidades de carácter para justificar mi amistad con él.

Ahora bien, más allá de cuáles hayan sido los factores particulares que generaron la relación de afecto mutuo, lo relevante para esta posición es que la existencia de la relación genera nuevas obligaciones. Una vez que tenemos amigos, contamos con nuevas razones para actuar, razones que se derivan de la historia de la relación antes que de nuestra preocupación por la virtud. Adoptando la distinción de Thomas Nagel entre razones relativas al agente y neutrales con relación al agente, Brink destaca lo siguiente:

Las razones para promover el bien o la virtud, en cuanto tales, son razones neutrales con relación al agente [agent-neutral], mientras que las razones para promover el bien de aquellos con los que el agente mantiene relaciones especiales son razones relativas al agente [agent-relative]. La amistad parece normativamente significativa porque es una relación que parece transformar las razones que el agente tiene independientemente de la relación. Si esto es así, nuestras razones para preocuparnos por nuestros amigos son relativas al agente e históricas, mientras que la concepción impersonal de la amistad las representa como neutrales respecto del agente [...]. A menos que nuestra concepción del amor y la amistad le asigne valor intrínseco a la relación histórica entre amigos, parece incapaz de justificar la preocupación por el amigo qua amigo. ${ }^{12}$

Cualesquiera que sean los factores causales que lleven a dos personas a ser amigas (su coincidencia en gustos estéticos, su sentido del humor, su misma concepción religiosa, etc.), lo cierto es que el tiempo y los acontecimientos que vivan en compañía generan una relación de afecto y cuidado mutuos, constituyendo una relación de la que se derivan ciertas obligaciones. Es la valoración de esas experiencias compartidas, de esa historia, la que genera obligaciones.

Yendo un poco más allá, Schoeman considera que a través de la interacción en el tiempo los amigos van redefiniendo mutuamente su identidad, al punto que "[s]e transforman en una comunidad única, con un ser y un valor propios". ${ }^{13}$ Cuando dos personas han adquirido un afecto mutuo y se han influido mutuamente para devenir las personas que son, la relación adquiere un valor intrínseco que justifica un tipo de consideración especial con el amigo que no se tiene con los demás.

${ }^{12}$ D.O. Brink, op. cit., pp. 269-270. Para la distinción entre razones neutrales y relativas al agente, véase T. Nagel, Una visión de ningún lugar, pp. 220-221.

${ }^{13}$ F. Schoeman, op. cit., p. 280. 
En el transcurso de nuestra vida, hechos contingentes y moralmente irrelevantes - como la coincidencia en disfrutar un deporte- determinan que entablemos un conjunto de relaciones más íntimas con ciertas personas. A través de la relación continuada, esas personas pasan a ocupar un lugar particularmente valioso en nuestras vidas. La historia compartida con ellos nos define en parte, y por lo mismo la relación es intrínsecamente valiosa.

Al asignar un valor intrínseco a la relación de amistad, de la que se derivan obligaciones especiales, los defensores de esta concepción asumen un conflicto potencial entre dichas obligaciones personales y las exigencias morales. Si bien podemos decir que debemos procurar el bien de nuestros amigos sin que eso implique ayudarlos a cumplir toda meta que se hayan fijado, ${ }^{14}$ lo cierto es que se considera que la amistad puede generar exigencias que entren en conflicto con las exigencias de la moral. Esto lo ha destacado Bernard Williams.

Según Williams, la relación de amistad con una persona particular es uno de esos proyectos básicos que conforman el carácter de las personas, esto es, proyectos que le dan sentido a sus vidas, por lo que "[p]uede llegar un punto en que sea bastante irrazonable que la persona, en nombre del buen orden imparcial del mundo de los agentes morales, renuncie a algo que es una condición para que tenga interés en estar en el mundo". ${ }^{15}$ Intentar subsumir las relaciones de amistad en relaciones morales es considerado por Williams directamente un absurdo. ${ }^{16}$ Si dos personas se están ahogando y una de ellas es una desconocida para mí, en tanto que la otra es mi amiga, está claro que

${ }^{14}$ Precisamente desde esta perspectiva se pone énfasis en distinguir el querer a la persona del querer algún rasgo de su carácter. Así, entre otros, Schoeman afirma: "Uno puede amar a su hijo pequeño, que es esencialmente inmaduro, sin por eso amar la inmadurez. Esta fusión de personas y rasgos de carácter, esta sinécdoque, es endémica en la discusión aristotélica de la amistad y es en parte responsable de su inadecuación. Caracteriza mal la lealtad a una persona el entenderla como si implicara un compromiso con los principios motivadores de esa persona" (F. Schoeman, op. cit., p. 273); y por su parte escribe Jeske: "si Henry no es bueno, parece que no puedo promover sus fines como 'bienes independientes' - sus fines simplemente no son bienes en absoluto. Este tipo de objeción, sin embargo, confunde la preocupación por una persona con la preocupación por sus fines subjetivos. Puedo preocuparme por Henry, por promover su bienestar y, sin embargo, puedo reconocer que él ha elegido perseguir fines dañinos y triviales" (D. Jeske, op. cit., p. 65).

${ }^{15}$ B. Williams, La fortuna moral, p. 28.

${ }^{16}$ Williams califica específicamente de absurda la posición de Richards, para quien desde la posición original se seguiría "un principio de amor mutuo que requiere que las personas no demuestren afecto personal y amor a otras exclusi-

Diánoia, vol. LV, no. 64 (mayo 2010). 
intentaré salvar a mi amiga, y carecerá de interés para mí el que haya o no una justificación imparcial para mi decisión. Si me pusiese a buscar esa justificación, estaría, según Williams, pensando de más. ${ }^{17}$ De modo que "una vez que la moralidad está ahí, y también las relaciones personales tomadas con seriedad, asimismo están ahí las posibilidades de que haya conflictos". ${ }^{18}$ En la medida en que la valoración intrínseca de las relaciones de amistad nos ofrece razones para actuar que son independientes de las razones que tenemos para actuar moralmente, surge la posibilidad de un conflicto entre ambas. Éste parece ser el precio que hemos de pagar por el hecho de asignarle valor intrínseco a la amistad.

\section{Problemas por resolver}

Como se ha planteado el debate, parece que, o bien asignamos un valor intrínseco a la relación de amistad - la cual implica la valoración de una historia compartida y de rasgos idiosincrásicos- y admitimos que es posible un conflicto entre las exigencias de esta relación y las exigencias morales, o bien asumimos una defensa impersonal de la amistad - justificada desde una concepción independiente de lo valioso-, por lo que la relación de amistad adquiere un valor instrumental, y no

vamente con base en características físicas arbitrarias, sino más bien con base en rasgos de personalidad y carácter relacionados con el actuar con base en principios morales" (D. Richards, A Theory of Reasons for Action, p. 94, citado por B. Williams, op. cit., pp. 30-31).

${ }^{17}$ Para Harry Frankfurt incluso el pensamiento de que una de las personas es mi amiga estaría de más; se supone que al ver la situación debo correr a socorrer a mi amiga, por lo que todo pensamiento estaría de más (véase H. Frankfurt, Las razones del amor, p. 51, n.). Si bien Williams analiza el ejemplo de Fried (en Ch. Fried, An Anatomy of Values, p. 227), en el que, en lugar de una persona amiga, quien se está ahogando es la esposa del posible socorrista, esta modificación es irrelevante a los efectos de la argumentación. Simplemente la he hecho para seguir concentrados en la amistad.

${ }^{18}$ B. Williams, op. cit., p. 31. En el mismo sentido va la posición de Jeske: "La concepción del sentido común considera que nuestras razones para actuar que surgen como resultado de nuestra participación en relaciones de amistad son razones que compiten con nuestras razones para promover el bien de cualquier persona, razones que pueden derivar de restricciones morales kantianas o de exigencias utilitaristas en relación con la promoción del bien en cuanto tal. Difiere del kantismo y del utilitarismo por considerar que nuestras razones para estar especialmente preocupados por nuestros amigos surgen en última instancia de esas relaciones y no de principios más generales" (D. Jeske, op. cit., p. 67).

Diánoia, vol. LV, no. 64 (mayo 2010). 
intrínseco, lo cual choca, entonces, con nuestras intuiciones más básicas. $^{19}$

Está claro que resulta atractiva la posición centrada en la relación en cuanto que le otorga valor intrínseco a la amistad, mientras que la concepción centrada en el tipo de persona resulta atractiva en cuanto que nos evita el conflicto entre exigencias normativas propias de la amistad y exigencias propias de la moralidad.

Más allá del ejemplo de Williams, lo cierto es que no deja de resultar contraintuitivo este conflicto de obligaciones. Efectivamente, parece inadmisible que uno abandone algunas obligaciones morales por el hecho de que, a partir de ir a jugar al fútbol todos los miércoles, ha adquirido un afecto (que es recíproco) por todos los miembros del equipo. Y no sólo resulta difícil de aceptar esta competencia de obligaciones, sino que también parece inadmisible que uno pueda ser amigo de una persona inmoral. Imaginemos a una persona lo bastante inescrupulosa en la persecución de sus fines personales como para tener muy poca consideración por la mayoría de las personas. ¿Es admisible que tengamos obligaciones hacia ella en virtud de alguna relación personal? ¿Es razonable sostener que, si bien disentimos con ella con respecto al trato que corresponde tener con los demás, somos amigos debido a toda una historia compartida, acompañada de mutuo afecto, y por lo tanto tenemos obligaciones hacia ella?

Cuando alguien nos trata injustamente - no en un caso particular, sino sistemáticamente y a causa de su carácter desconsiderado- no sólo condenamos moralmente la actitud de quienes, por considerarse amigos de tal persona, mantienen silencio, complicidad o simplemente se despreocupan del asunto, sino que nos resulta inadmisible que puedan ser sus amigos. Suponemos que para ser amigo de alguien, ese

${ }^{19}$ Podemos percibir en tal oposición de perspectivas una analogía con el debate en torno a la valoración de las relaciones políticas. Así, mientras el comunitarismo pretende otorgar valor intrínseco a las relaciones políticas entre personas con una historia compartida y rasgos idiosincrásicos comunes, el liberalismo de izquierda considera que las relaciones políticas son valiosas en la medida en que se vinculan con cierta concepción de justicia. Y mientras este último considera que los rasgos idiosincrásicos y contingentes no pueden determinar las obligaciones políticas, los comunitaristas consideran que es un error otorgar a la participación política un valor meramente instrumental. Desarrollo esta analogía en M. Daguerre, "Entre el humanismo cívico y el liberalismo de izquierda", donde propongo una concepción de las relaciones políticas análoga a la concepción de las relaciones de amistad que defiendo en este trabajo, concepción que permite superar lo que Ronald Dworkin, en Ética privada e igualitarismo político, ha llamado el problema de la fuerza categórica, el cual aqueja tanto al comunitarismo como al liberalismo. 
alguien debe cumplir con algunos requisitos. No se puede ser amigo de cualquiera. Consideramos pertinente exigir una justificación convincente a quien mantiene una relación de amistad con alguien inmoral. Seguramente no nos bastaría la explicación de que lo conoce desde hace años y han compartido vacaciones, etc. Suponemos que la inmoralidad de la persona es un hecho relevante para reconsiderar la relación con ella.

Si bien en este sentido resulta más atractiva la posición centrada en el carácter del amigo, desde otra perspectiva resulta más convincente la posición centrada en la relación. Está claro que vivimos las relaciones de amistad como valiosas en sí, y no por su capacidad para desarrollar un bien independiente de ellas, cualesquiera que sean los fines de las personas virtuosas. ${ }^{20}$

Considero que una concepción satisfactoria de la amistad debe ver el modo de sostener tanto el valor intrínseco de la relación, como su compatibilidad con otras exigencias normativas, no derivadas de una relación de amistad.

\section{Una tercera concepción, centrada en el tipo de relación}

Las dos posiciones que se distinguen en el debate contemporáneo han querido dar lugar a la idea aristotélica de que debemos querer al amigo por el amigo mismo. Esto puede significar querer al amigo por el tipo de persona que es, y no por la relación que tiene con uno, o quererlo porque es nuestro amigo, y no por el aporte que a través de la relación con él podemos hacer a algo independientemente valioso.

Este énfasis en querer el bien del amigo por el amigo mismo no permite destacar el lugar que la reciprocidad tiene en la amistad. Si amamos al otro por el otro mismo, y a su vez el otro nos ama por nosotros mismos, podemos decir que la reciprocidad resulta de dos estados personales independientes, y no influye en la configuración de

${ }^{20}$ Posiblemente esta valoración intrínseca tenga una explicación evolutiva. Según Richard Wilkinson, en virtud de la importancia de las relaciones sociales para la supervivencia, "tenemos razones para pensar que las presiones altamente selectivas nos han dotado del deseo de la amistad y de una tendencia a considerar el rechazo o la falta de amigos como fuente de ansiedad" (R. Wilkinson, Las desigualdades perjudican, p. 55). Téngase en cuenta que, si bien el deseo de lograr ciertas relaciones cooperativas nos proporciona enormes ventajas desde un punto de vista evolutivo, ello no quiere decir que deseemos tales relaciones en virtud de esas ventajas, ya que la evolución no procede estratégicamente. El dar un valor intrínseco a las relaciones no competitivas es lo que nos ha permitido evolucionar. 
tales estados. Desde esta perspectiva, quien ama a otra persona quiere el bien de ésta, más allá de cuál sea la disposición del amado hacia él. ${ }^{21}$

Sin embargo, considero que la amistad supone un lugar más central para la reciprocidad. La amistad supone cierta disposición que sólo se da si existe reciprocidad, y se mantiene en tanto un amigo tenga hacia el otro una disposición similar a la que el otro tiene hacia él. No se trata de que el afecto por el amigo sea condicional, esto es, que esté sujeto a que el otro sienta un afecto similar (aunque esto también puede ser así). De lo que se trata es de que el afecto mutuo propio de los amigos va de la mano con la existencia de una disposición recíproca a realizar un conjunto de acciones; una disposición recíproca a realizar tanto un conjunto de actividades compartidas placenteras (dialogar, ir al cine, hacer deporte, etc.) como un conjunto de acciones que implican un sacrificio individual con vistas a ayudar al otro (se supone, por ejemplo, que al encontrarse uno en problemas, espera de los amigos un tipo de ayuda que no puede exigirse a un desconocido). ${ }^{22}$ Si quien es considerado un amigo no responde con la acción esperada,

${ }^{21}$ En Aristóteles esto parece claro: "decimos que debe desearse el bien del phílos por el phílos mismo. De los que así desean el bien de otro, decimos que son benévolos si de la parte del otro no se produce el mismo sentimiento, pues cuando la benevolencia es recíproca decimos que es philía" (Aristóteles, Ética a Nicómaco, 1155b). De todos modos, el propio Aristóteles parece reconocer que la philía es más que benevolencia recíproca. Asi, en 1167a afirma: "tampoco es posible ser amigos sin haber sentido benevolencia, pero los que la sienten [...] únicamente desean el bien de aquellos para quienes tienen benevolencia, pero no harían nada con ellos ni se tomarían ninguna molestia por ellos", que es lo que se espera de los amigos. De modo que la philía genera una disposición favorable a realizar un conjunto de acciones, disposición que está ausente cuando sólo sentimos benevolencia por el otro.

Más allá de esto, la philía aristotélica parece ser un tipo de relación diferente de lo que contemporáneamente entendemos por amistad. Si la philía aristotélica (habitualmente traducida como amistad) implica el ser virtuoso, la convivencia $\mathrm{y}$, en definitiva, compartir todas las actividades vinculadas con el buen vivir, se trata de una relación en la que se involucran quienes están dispuestos a buscar juntos, permanentemente, la realización plena en la vida. Que Aristóteles no se haya referido al buen matrimonio (o a la buena relación de pareja) como el ejemplo más acabado de la philía posiblemente se deba, como sostiene Nussbaum, a sus ideas sobre la inferioridad femenina. Pero si aceptamos que la philía aristotélica se refiere a este tipo de relaciones, no podemos traducirla sin más como amistad, como también destaca Nussbaum (véase M. Nussbaum, La fragilidad del bien, cap. 12).

${ }^{22} \mathrm{Y}$ se supone que la ayuda esperada es una que estaría dispuesto a dar quien la demanda. 
la relación se replantea y podrá concluirse que la relación no era tan profunda, o que simplemente no existía una relación de amistad con tal persona. Y con el replanteamiento de la relación también habrá una modificación del tipo de cosas que uno está dispuesto a hacer por el otro.

De modo que la amistad supone cierta disposición entre los amigos, pero tal disposición no es independiente de la existencia de reciprocidad. En la medida en que no haya reciprocidad, tal disposición se verá modificada. De no hacerlo, estaríamos frente a una relación diferente, como puede ser la de un amor no correspondido, donde uno está dispuesto a hacer por el otro cosas que el segundo no haría por el primero.

Destaquemos que no es la acción en sí misma lo determinante, sino la disposición a realizarla. Quizá uno no necesite nunca que le hagan un favor, pero eso no quita que suponga en los amigos la disposición a hacérselo si fuera necesario. $Y$ cuando uno hace un sacrificio por un amigo espera que su amigo haga algo similar por él sólo si resulta necesario. La ayuda no se concibe como un préstamo que uno espera cobrar más adelante y tampoco se entiende desde un punto de vista estratégico, como medio para un fin diferente de la relación misma. La acción forma parte del fin mismo en la medida en que es la actualización de la disposición misma que define a la amistad.

Imaginemos una persona que se encuentra desconsolada por una razón cualquiera. Puede que un amigo suyo no sepa de qué modo ayudarla a superar su estado, o quizá piense que sólo el tiempo puede "curarla". Aun así, se supone que no corresponde que se desentienda de la situación. Puede actuar de un modo que, según supone, no será la solución al problema, y lo hará por el mero hecho de mostrar que tiene la disposición; así, puede hacer lo que le solicita su amigo incluso si considera que tal acción no es la solución a su problema. Obviamente, esto no quita que busque el mejor modo de ayudar, pero aun cuando no está clara la solución, actúa de algún modo y lo hace intentando dejar en claro que su disposición existe.

La amistad, por lo tanto, supone mutuo afecto acompañado de una disposición recíproca a realizar un conjunto de acciones. Y en una relación de amistad la existencia de reciprocidad es la que va calibrando las disposiciones personales, por lo que no puede decirse que éstas sean independientes de la reciprocidad. Si me encuentro en una situación difícil, el grado en que se impliquen en ella mis diferentes amigos calibrará mi futura disposición hacia ellos, ya sea intensificando la relación, manteniéndola igual o debilitándola. 
Consolidar este tipo de relaciones nos resulta intrínsecamente valioso. Cuando compartimos momentos agradables con amigos, o cuando estamos convencidos de que ellos estarían dispuestos a hacer por nosotros ciertos sacrificios porque saben que nosotros también estamos dispuestos a hacer lo mismo por ellos, recibimos una satisfacción que no es producto de la valoración del coraje, la justicia, etc. Lo que se valora es la relación, por las características propias de esa relación. El acento no hay que ponerlo en el carácter del amigo, sino en ciertos rasgos definitorios de la relación de amistad. Son éstos los que valoramos cuando hablamos de amistad. De aquí que la relación tenga un valor intrínseco y no como instrumento para el desarrollo de otros valores, como la justicia. ${ }^{23}$

Desde esta concepción, la virtud adquiere un significado al interior de la relación. Más allá de lo valiente, generoso, prudente, amable e inteligente -e incluso más allá de que sus fines sean loables o frívolos-, lo cierto es que todo amigo debe ser virtuoso en el sentido de tener la capacidad de poder cumplir con exigencias normativas propias de la relación misma de amistad que pueden entrar en conflicto con fines estrictamente personales. Si padecemos de una fuerte debilidad de la voluntad, resultará imposible tener una verdadera relación de amistad, ya que nunca responderemos del modo en que los amigos lo esperan. Podemos decir, en relación con la virtud implicada en la amistad, lo mismo que señala Foot con respecto a la justicia: "El hombre que posee la virtud de la justicia no está dispuesto a hacer ciertas cosas, y si se le tienta muy fácilmente, diremos que después de todo sí estaba dispuesto." 24 Quizá podamos ser muy condescendientes con quien consideramos nuestro amigo, perdonándole todos sus desplantes; pero, bien mirada la relación, estaríamos dispuestos a sostener que quien continuamente es desleal con su condescendiente amigo no es verdaderamente un amigo. Por lo tanto, no podemos decir que exista realmente en este caso una relación de amistad.

Por otra parte, contra lo que opina Whiting, si bien el logro de una conducta más o menos virtuosa será una condición necesaria para la consolidación de la relación de amistad, no será nunca condición suficiente. Una persona que siga cierta interpretación de los imperativos cristianos quizá lleve a cabo los mismos actos que un amigo realizaría por nosotros, pero no por ello se constituirá en nuestro amigo. Es ne-

${ }^{23}$ Pero precisamente en la medida en que la relación es valiosa en virtud de ser el tipo de relación que es, no adquiere su valor debido a rasgos idiosincrásicos ni por acontecimientos históricos. Más adelante volveré sobre esto.

${ }^{24}$ P. Foot, Las virtudes y los vicios, p. 153.

Diánoia, vol. LV, no. 64 (mayo 2010). 
cesario, para esto último, que valore la relación misma, que la disfrute. Como sostiene Thomas Scanlon, "una persona que no viese la amistad como un bien para ella misma, que no disfrutase de ella y que no la viese como un ingrediente importante de una vida buena, no sería tampoco un amigo de verdad, seguiría tan sólo un frío imperativo". ${ }^{25}$ Una persona puede ser justa, honesta, sincera, solidaria y tener todas las cualidades de carácter que nos parezcan valiosas, y aun así no pertenecer al universo de los amigos potenciales, ya que si no valora la relación por sí misma, si no disfruta de ella, no puede contar como amigo.

Pero de nuevo, si bien no es por la virtud por la que hacemos amigos, lo cierto es que no podemos ser amigos de aquel que es incapaz de dejar sus intereses estrictamente personales a un lado. En suma, la amistad es una relación valiosa que requiere cierto carácter virtuoso, pero que no se persigue teniendo como motivación lograr tal carácter o contribuir al desarrollo de un carácter de ese tipo. ${ }^{26}$

¿Quiénes, entonces, son nuestros amigos potenciales? ¿Todos -como sostiene, por ejemplo, Jeske- o sólo los virtuosos, como afirma Whiting? Desde mi perspectiva, son amigos potenciales todos aquellos que valoren la relación tal como la he definido, y que no sean tan débiles de voluntad como para privilegiar sistemáticamente su comodidad o sus fines estrictamente individuales frente a las exigencias de la relación de amistad. La valoración, como ya señalé, debe ser intrínseca y su presencia posiblemente se explique, como han señalado diversos investigadores, por las presiones evolutivas de la selección natural. Si admitimos que esta valoración es universal, diremos que todos son amigos potenciales. Si no lo admitimos, diremos que sólo aquellos que valoran esas relaciones pueden ser amigos; pero aun si la valoración es universal puede que, por ejemplo por factores culturales, haya quedado

${ }^{25}$ T. Scanlon, Lo que nos debemos unos a otros, p. 210.

${ }^{26}$ En este sentido, tampoco coincido con Brink, quien distingue entre a quién querer y cómo querer. Según él, cuando Platón y Aristóteles analizan la relación entre la amistad y la virtud estarían diciendo que, dado que queremos el bien del amigo, lo que debemos hacer es procurar que desarrolle un carácter virtuoso, pues sólo tal carácter lo conducirá a la felicidad (véase D.O. Brink, op. cit.). Desde mi perspectiva, la relación de amistad no implica ninguna preocupación especial por el carácter del amigo. Esta posición permite dar sentido a la amistad entre niños. Efectivamente, no consideramos que los niños sean virtuosos ni que tengan una preocupación especial por lograr que el amigo sea virtuoso; sin embargo, muy bien pueden valorar la relación de amistad tal como la he definido, y la relación exigirá que sean capaces, en ciertas situaciones, de posponer su beneficio personal. Agradezco la sugerencia de uno de los árbitros de explicitar este punto. 
ahogada por las presiones sociales para perseguir exclusivamente fines estrictamente personales, de modo que muchas personas se han vuelto incapaces de actuar de acuerdo con las exigencias propias de la relación de amistad. ${ }^{27}$ Quien sólo está dispuesto a relacionarse con otros por consideraciones estratégicas, como medios para la consecución de fines estrictamente personales, no puede entrar en una relación de amistad. De modo que no todos son dignos de ser amigos, pero tampoco lo son únicamente quienes poseen un carácter virtuoso.

¿Qué lugar tienen aquí los rasgos arbitrarios, los accidentes históricos y los psicológicos? En este sentido no hay diferencias con ninguna de las posiciones. Una vez recortado el universo de amigos potenciales, los rasgos arbitrarios serán los que determinarán el ser amigo de éste y no de aquél, el sentir afecto por uno y no por otro. Así, mi lugar de residencia llevará a que interactúe con unos y no con otros, así como mi gusto por ciertos deportes y cierta música, y mis ideas religiosas, políticas, etc. Tales interacciones no sólo irán dando origen a un sentimiento afectivo por el otro, sino que me permitirán evaluar (no necesariamente de manera explícita y consciente) la real valoración que ese otro tiene de las relaciones de amistad.

Ahora bien, en la medida en que entendamos que las relaciones de amistad suponen una disposición recíproca a realizar un importante conjunto de acciones con o por el amigo, está claro que no podremos ser amigos de todo el mundo. No puedo juntarme a cenar con todo el mundo, ni utilizar mi tiempo libre para ayudarlos a arreglar su casa, etc. Así, calibrando las disposiciones recíprocas vamos estableciendo

${ }^{27}$ Ésta parece ser efectivamente la tendencia, y se corre el riesgo de que se consolide. Según recientes investigaciones de Juliet Schor, "[e]n todo el sector del marketing infantil, el uso de unos niños para atraer a otros es una práctica que se extiende con celeridad. Una de las razones principales para explicarlo es que la palabra de un amigo constituye una de las pocas fuentes de credibilidad que subsiste en un mundo sobresaturado de mensajes comerciales [...]; si persiste esta moda de pagar por anunciar productos mediante la técnica del boca-oreja, es posible que la gente acabe desarrollando una mayor reserva al respecto y aprenda a identificar a aquellos conocidos que le recomiendan cosas instrumentalizados por alguna empresa [...]. Los profesionales del marketing están enseñando a los niños a ver a sus amigos como fuentes lucrativas que pueden explotar para obtener productos o dinero [...]. Pero la importancia de la amistad radica precisamente en el hecho de mantenerse al margen de presiones comerciales. Se considera de los últimos bastiones de la no instrumentalización, un baluarte contra los valores del mercado y los comportamientos basados en el interés propio que dominan nuestra cultura. Por ello valoramos tanto nuestras amistades. Y por ello, precisamente, a los profesionales del marketing les interesa tanto" (J. Schor, Nacidos para comprar, pp. 106-107).

Diánoia, vol. LV, no. 64 (mayo 2010). 
algunas relaciones más estrechas, y en la medida en que éstas se van consolidando podríamos decir que vamos cubriendo la cuota de relaciones de amistad que podemos asumir. Si queremos mantener tales relaciones de amistad, no podremos acumular relaciones del mismo tipo con muchas personas.

Según mi interpretación, entonces, la amistad es una relación que se da cuando existe afecto mutuo, una disposición recíproca a realizar un determinado conjunto de acciones y una valoración intrínseca de la relación así definida. La amistad efectivamente supone la coincidencia en cierta valoración, pero no se trata de que dos personas valoren algo que es independiente de la relación. Dos personas que valoren la honestidad, la justicia, la veracidad o virtudes similares no necesariamente entrarán en una relación de amistad. Lo que deben valorar es el tipo de relación misma que es la amistad, no el tipo de persona que es el amigo. No hay un tipo de persona al que podamos presentar como el paradigma del amigo, aunque sí hay condiciones mínimas que toda persona debe cumplir para ser amigo.

Por lo tanto, la valoración de este tipo de relaciones no se deriva de ningún rasgo particular del amigo. No sólo no se deriva del carácter virtuoso del amigo, sino que tampoco se deriva de que el amigo sea aquel que compartió con uno un conjunto de experiencias y que contribuyó a conformar la identidad de uno. Cabe suponer que es natural desear tener amigos; como dice Schoeman: "Está en nuestra naturaleza el vivir con otros y el querer compartir nuestras vidas y destinos con ellos". ${ }^{28}$ Pero si bien el afecto mutuo puede surgir de haber pasado ciertos momentos juntos, de haber superado codo con codo grandes dificultades, de coincidir en creencias religiosas, gustos estéticos, deportivos, etc., no son tales acontecimientos los que otorgan valor normativo a la relación. El vivir una relación en la que existe una disposición recíproca a realizar un conjunto importante de acciones es lo que tiene valor en sí. Puedo recordar con mucho cariño los acontecimientos vividos con un amigo, pero si éste se comporta de manera desleal en el presente, no habrá modo de que continúe siendo mi amigo; no hay historia vivida que pueda permitir las deslealtades presentes. ${ }^{29}$ La amistad efectivamente supone que los amigos le den importancia a su relación, pero

${ }^{28}$ F. Schoeman, op. cit., p. 281.

${ }^{29} \mathrm{Y}$ como ya señalé, si la persona que sufre la deslealtad desea perdonar continuamente al otro, diríamos que, antes que una relación de amistad, existe una relación de amor incondicional. Nadie diría del desleal que es un verdadero amigo del otro, y como la amistad exige reciprocidad, no es posible la amistad con el desleal. 
no porque constituya una parte ineludible de su historia. Incluso puede darse el caso de que dos amigos prefieran olvidar su historia de constantes desencuentros y desacuerdos, incluso de enemistad, pues ése es el mejor modo de conciliar sus sentimientos con la consabida disposición recíproca que ahora mantienen.

No es relevante cuál es el factor que permitió a los amigos estar convencidos del afecto y la disposición mutua. No importa si se debió al hecho de compartir una historia, de coincidir en una ideología o en una religión o en su moral kantiana. Lo relevante para que efectivamente se dé una relación de amistad es que exista una valoración del tipo de relación que es la amistad, y el afecto y disposición mutua que la hacen realidad.

El hecho de que en las comunidades pequeñas se den, conjuntamente, una coincidencia en la concepción sustantiva de la vida buena y una disposición a cooperar entre todos — disposición que a menudo no se extiende a quienes están fuera del grupo- puede llevarnos a pensar que la primera es condición necesaria de la segunda. Sin embargo, esto no puede tomarse como evidencia en contra de la existencia de una disposición universal a cooperar con todos aquellos que cooperen con nosotros. El carácter generalmente acotado de nuestra disposición a cooperar bien puede explicarse por el hecho de que no estamos seguros de que tal disposición desempeñe un papel importante en la conducta de personas que no conocemos. Podemos dudar de que valoren las relaciones de amistad o de que tengan la capacidad de sacrificar, en ocasiones importantes, sus intereses personales en función de las demandas de amistad, razón por la cual se comprende que sólo estemos bien dispuestos con respecto a aquellos de quienes circunstancias fortuitas nos han permitido constatar, o nos autorizan a suponer, su buena disposición. Así, los miembros de una institución religiosa cuentan con situaciones en las que se puede demostrar una valoración de la relación y una buena disposición hacia el otro, por lo que la reciprocidad puede establecerse. Pero estas contingencias sólo pueden determinar que sea amigo de éste y no de aquél; no son, en cambio, la fuente que otorga valor a la relación. Las contingencias históricas y psicológicas no deben cumplir su papel en la justificación de las relaciones valiosas, sino en la explicación de por qué, contingentemente, se han dado estas relaciones y no otras.

Vayamos ahora al importante problema del conflicto entre la amistad y la moralidad. Considero que Thomas Scanlon ha analizado correctamente este punto. Este filósofo parte de la crítica de Williams a Fried a la que me referí anteriormente: 
Williams considera la sugerencia de que, en una situación en la que, dadas dos personas, sólo se pueda salvar a una de ellas, sería contrario a la consideración imparcial de cada persona que esas concepciones de la moralidad exigiesen salvar a una de ellas en virtud de algún vínculo especial, como por ejemplo, que dicha persona fuera un amigo o un cónyuge. Lo que aquí se plantea no es un simple conflicto práctico. La sugerencia es que una moralidad que requiriese ese tipo de imparcialidad (que declarase que el amor, o la amistad, son razones inadmisibles para salvar a una persona en vez de a otra) eliminaría el amor y la amistad, pues es esencial a estas relaciones el que en esa situación uno tenga razones para otorgar primacía al amigo o a la persona querida. ${ }^{30}$

Scanlon destaca que solemos ver en las relaciones morales sólo el aspecto negativo: la sensación de obligación y de culpa. Sin embargo, al igual que en las relaciones de amistad, éstas tienen un aspecto positivo. Valoramos vivir con los demás según pautas morales: "Trabar esta relación con los demás es algo atractivo en sí mismo; es decir, la relación merece ser buscada por sí misma." ${ }^{31}$ Más allá de la discusión de cuáles son las pautas morales que debemos adoptar, coincido con Scanlon en que hay cierto modo de interactuar con aquellos que no conforman nuestro círculo íntimo que resulta valioso en sí mismo. Así como seguramente nos afecte negativamente vivir en una sociedad en la que se desconoce el respeto, valoramos intrínsecamente el pertenecer a sociedades en las que nunca está en juego nuestra dignidad, donde se resuelven los conflictos en un marco de razonabilidad, etcétera.

Así como las relaciones morales tienen su aspecto positivo, Scanlon también destaca que las relaciones de amistad tienen su aspecto negativo en el sentido de que conllevan obligaciones, exigencias de lealtad que pueden requerir sacrificar metas personales. Las relaciones de moralidad y amistad son análogas, sólo que en las primeras solemos resaltar los aspectos negativos, mientras que en las segundas nos centramos en los positivos.

Si aceptamos tal analogía, las obligaciones derivadas de las relaciones de amistad no se enfrentan a obligaciones absolutamente impersonales, sino que se enfrentan a las obligaciones derivadas de relaciones no tan estrechas. Frente a este conflicto, de todos modos tendemos a pensar que, dado que las primeras son en un sentido más fuertes, cualquier conflicto entre ellas irá en desmedro de las relaciones morales. Sin

${ }^{30}$ T. Scanlon, op. cit., p. 208.

${ }^{31}$ Ibid., p. 210.

Diánoia, vol. LV, no. 64 (mayo 2010). 
embargo, esto es un error. Del hecho de que la relación sea más intensa e implique una disposición a hacer más cosas por el amigo que por un desconocido no se sigue que uno estará dispuesto a hacer cualquier cosa por el amigo, sin importar cuán graves sean las consecuencias, para el desconocido, de nuestro incumplimiento de las obligaciones que tenemos hacia él.

Si entendemos que ciertas relaciones - entre las cuales incluimos las de amistad, de pareja y morales - son realmente valiosas, el hecho de que algunas sean más valiosas que otras no anula el deseo de volverlas compatibles. Está claro que no querremos definir las relaciones más básicas - las morales - de modo que las exigencias implicadas por ellas puedan ir en detrimento de las relaciones más estrechas. Pero si tales relaciones básicas tienen un valor en sí, deberemos definir las más estrechas de modo que, en circunstancias normales, nos permitan consolidar a las más básicas.

Así, si un amigo posee un sentido del humor ácido, si le divierte el hecho de que personas desconocidas tengan que pasar por situaciones embarazosas y desea fervientemente que participemos de sus bromas, está claro que tiene sentido negarnos en virtud de que consideramos que las exigencias que se derivan de mi relación con el desconocido son de mayor peso que la exigencia de mi amigo. La relación de amistad estaría derivando en una relación patológica si exigiese cumplir con los caprichos del amigo, aun cuando éstos implican un perjuicio en la autoestima de los demás. Del mismo modo, si bien se comprende que toda persona se preocupará mucho más por lo que beneficia o perjudica a su pareja, entendemos que esta preocupación debe tener un límite; posiblemente a nadie le choque el que una persona haya dejado de lado temporalmente su actividad profesional para poder dedicarse a cuidar de la salud de su pareja, pero sí resultará inadmisible que abandone sus guardias en el hospital porque su pareja lo invita a cenar.

El ejemplo de Williams no sería pertinente porque en él no se dan las condiciones como para que uno pueda cumplir con todas las exigencias. La exigencia básica es salvar a quien está por ahogarse. Esta exigencia se deriva de ambas relaciones: la que tengo con mi amigo y la que tengo con el desconocido. Simplemente no puedo cumplir con ambas. Valoro ambas relaciones, pero tengo que optar por una: está claro que optaré por la de amistad, porque valoro más la relación con mi amigo que la relación con el desconocido. No se trata de que se hayan dado exigencias conflictivas, pues, como ya destaqué, resulta absurdo definir las relaciones más básicas de un modo que sus exigencias puedan ir en 
detrimento de las relaciones más estrechas. La relación moral con un desconocido puede hacer que, si las condiciones lo permiten, acuda en su ayuda en casos en que la vida del desconocido corra peligro. Pero está claro que, en el caso que analiza Williams, las condiciones no lo permiten. El que en el mismo momento mi amigo se esté ahogando es un hecho análogo al que se daría si yo no supiese nadar: es un factor que impide considerar que exista una obligación con el desconocido, obligación que, en otras circunstancias, sí tendría. Así, quien terminará ahogándose en el caso de Fried no podría verse traicionado, pues en tales circunstancias el socorrista no tenía ninguna obligación con él. En otra dimensión, ¿qué amigo se sentiría traicionado si uno no lo rescatase porque prefirió rescatar a su hijo? Es más, uno no sabría ante qué tipo de persona se encuentra si ésta sometió a un procedimiento imparcial el decidir si salvar a su hijo o a su amigo.

En definitiva, la amistad supone una valoración de un tipo de relación entre iguales, una relación en la que ambos sienten afecto por el otro y están dispuestos a realizar un conjunto de acciones con el otro y por el otro. A qué se supone que deben estar dispuestos y el grado de afecto mutuo dependerán de cada relación de amistad. Ahora bien, si admitimos que las relaciones con quienes no son nuestros amigos también pueden resultar valiosas, las relaciones de amistad deberán ser sustantivamente definidas de modo que den lugar a estas otras. Pero estas otras relaciones, como dijimos, tampoco podrán ir en detrimento de la existencia de relaciones de amistad.

\section{Conclusión}

La amistad, en virtud de las obligaciones que genera, parece requerir algún tipo de justificación. Sentimos que tenemos más obligaciones con algunas personas que con otras, y nos parece que está bien que así sea. Teniendo en cuenta este único aspecto, concepciones impersonales como la de Whiting parecerían ir en la dirección correcta. Al centrarse en un tipo de persona, y no en el hecho contingente y moralmente arbitrario de haber compartido ciertos acontecimientos con el otro, está en condiciones de justificar el valor normativo de la amistad. Sin embargo, su valor resulta instrumental, derivado de su aporte potencial al desarrollo de algo independientemente valioso. Es en este punto que resulta más persuasiva la posición contraria, que otorga un valor intrínseco a la relación de amistad.

Ahora bien, si en vez de otorgarle valor al tipo de persona que el amigo debe ser le otorgamos valor al tipo de relación (y no a la his- 
toria particular que la generó) que la amistad es, podemos defender una concepción de la misma que resulte intrínsecamente valiosa, a la vez que, por haber quitado relevancia a los factores históricos y psicológicos contingentes, no necesita admitir un conflicto potencial con las exigencias propias de las relaciones morales.*

\section{BIBLIOGRAFÍA}

Aristóteles, Ética a Nicómaco, 6a. ed., trad. María Araujo y Julián Marías, Centro de Estudios Constitucionales, Madrid, 1994.

Bennett, H., "Friendship", The Stanford Encyclopedia of Philosophy [en línea], ed. E. Zalta, Center for the Study of Language and Information-Stanford University, 2005, disponible en: < http://plato.stanford.edu/archives/sum 2005/entries/friendship/>.

Brink, D.O., "Eudaimonism, Love and Friendship, and Political Community", Social Philosophy and Policy, vol. 16, 1999, pp. 252-289.

Daguerre, M., "Entre el humanismo cívico y el liberalismo de izquierda", Isegoría, no. 33, 2005, pp. 249-261.

Dworkin, R., Ética privada e igualitarismo político, trad. Antoni Domènech, Paidós, Barcelona, 1993.

Foot, Ph., Las virtudes y los vicios y otros ensayos de filosofía moral, trad. Claudia Martínez, Instituto de Investigaciones Filosóficas-UnAM, México, 1994.

Frankfurt, H., Las razones del amor, trad. Carme Castells, Paidós, Barcelona, 2004.

Fried, Ch., An Anatomy of Values, Harvard University Press, Cambridge, 1970.

Jeske, D., "Friendship, Virtue, and Impartiality", Philosophy and Phenomenological Research, vol. 57, no. 1, 1997, pp. 51-72.

Nagel, Th., Una visión de ningún lugar, trad. Jorge Issa González, Fondo de Cultura Económica, México, 1998.

Nussbaum, M., La fragilidad del bien. Fortuna y ética en la tragedia y la filosofía griega, 2a. ed., trad. Antonio Ballesteros, Antonio Machado Libros, Madrid, 2004 (La Balsa de la Medusa, 77).

Richards, D., A Theory of Reasons for Action, Oxford University Press, Nueva York, 1971.

Scanlon, Th., Lo que nos debemos unos a otros, trad. Ernest Weikert García, Paidós, Barcelona, 2003.

*Este trabajo forma parte de las investigaciones realizadas en el marco del proyecto "Equilibrio reflexivo, ética y teoría política republicanas", financiado por la Universidad Nacional de La Plata (H490) y por la Agencia Nacional para la Promoción de la Ciencia y la Tecnología (PICT2006-01795). Agradezco las observaciones que me hicieron Félix Ovejero, Victoria Costa y María Julia Bertomeu. Agradezco especialmente a Julieta Elgarte, quien leyó varios borradores y contribuyó considerablemente a mejorarlos. 
Schoeman, F., "Aristotle on the Good of Friendship", Australasian Journal of Philosophy, vol. 63, no. 3, 1985, pp. 269-282.

Schor, J., Nacidos para comprar, trad. Juanjo Estrella, Barcelona, Paidós, 2006.

Whiting, J., "Impersonal Friends", Monist, vol. 74, 1991, pp. 3-29.

Wilkinson, R., Las desigualdades perjudican, trad. Silvia Furió, Crítica, Barcelona, 2001.

Williams, B., La fortuna moral, trad. Susana Marín, Instituto de Investigaciones Filosóficas-UnAM, México, 1993.

Recibido el 18 de diciembre de 2008; aceptado el 14 de octubre de 2009. 